\title{
AMAZÔNIA EM DESENVOLVIMENTO ENTRE O PROGRESSO E O REGRESSO: UM OLHAR CRÍTICO SOBRE A MEMÓRIA BIOCULTURAL
}

RESUMO: O presente artigo apresenta uma possível chave de leitura no que se refere aos conceitos de progresso ambiental, partindo de um contexto amazônico. $\mathrm{O}$ texto tem por base uma relação entre a sociedade considerada moderna e os povos considerados primitivos ou rústicos (povos da floresta) no modo de pensar o progresso e o desenvolvimento ambiental. Também se procura abordar as origens do conceito moderno de progresso, sua aplicação no contexto atual e as implicações das práticas da economia, da política, do desenvolvimento da Amazônia que daí surgem, sobretudo, no impacto que tudo isso provoca na vida do homem amazônico. Trabalham-se ainda a noção do significado do termo regresso e o que ele pode representar para as populações da floresta, além de um alerta para a retomada da memória biocultural.

PALAVRAS-CHAVE: Homem e natureza; Cultura; Conhecimento; Mudança; Comunidade.

\section{DEVELOPING AMAZON BET WEEN PROGRESS AND REGRESSION: A CRITICAL VIEW ON BIO-CULTURE MEMORY}

ABSTRACT: Current study may provide a key interpretation on the concepts of environmental progress from the Amazon context, based on the relationship between the so-called modern society and primitive or rustic populations (people of the forest) in their way of thinking progress and environmental development. The origins of the modern concept of progress are analyzed, coupled to its application within the current context and the implications of the Amazon's economic, political and development practices, especially its impact on Amazon populations. The meaning of regression and what it means for forest peoples are investigated, whilst bio-culture memory is retrieved.

KEY WORDS: Humans and Nature; Culture; Knowledge; Change; Community.

Graduada em Filosofia pela Faculdade Pan Americana (FPA), Graduanda do curso de Engenharia Ambiental e Energias Renováveis pela Universidade Federal Rural da Amazônia (UFRA). Docente na rede particular de educação. Brasil. E-mail: marilzabulhoes@hotmail.com 


\section{INTRODUÇÃO}

A Amazônia é um território que constantemente se encontra em crise, sobretudo se compreendermos o significado grego da palavra, isto é, mudança. As crises ou mudanças ocorridas no território em questão são - como sabemos de ordem natural e de ordem socioambiental. A primeira ordem se refere à crise imposta pela natureza sobre si mesma, são aquelas mudanças ocorridas no meio ambiente de forma espontânea e que nenhum ou pouco prejuízo trazem para a vida. A segunda ordem tem como principal autor o homem que, em seu contexto social, utiliza a natureza de acordo com suas necessidades, podendo, assim, causar muito ou pouco impacto na ordem natural, de acordo com as formas de interferência, aplicadas sobre a natureza.

Uma ideia ou um conceito foi determinante para impulsionar a maior crise ambiental já ocorrida na história, o desenvolvimento ambiental. Este termo desenvolvimento, em qualquer sentido, político, econômico, social, religioso ou ambiental, tem como significados mais comuns o crescimento, o melhoramento e o fortalecimento de algo. Portanto, o termo desenvolvimento, aplicado à natureza, significaria melhorá-la, torná-la mais perfeita. Será isso possível?

\section{CULTURA E NATUREZA: A MEMÓRIA BIOCULTURAL}

Do processo de evolução, até chegarmos à condição de homo sapiens sapiens, o traço social esteve presente, garantindo proteção ao grupo, transmitindo conhecimento, de forma que essa evolução garantiu que sua vida social se complexificasse com esforços cooperativos, ou seja, o traço de sua condição social parecia já estar esboçado, a saber, o homem sempre viveu em pequenos ou grandes grupos, em pequenas ou grandes aldeias, sempre teve uma vida social.

Esta vida social esteve sempre ligada ao ato de o homem se constituir como espécie biológica que, como toda espécie, está ligada ao meio ambiente ao qual pertence a natureza que a rodeia. Nesse sentido, os autores Victor M. Toledo e Narciso Barrera-Bassols escrevem: 
Antes de sermos seres sociais, fomos, somos e continuaremos a ser uma espécie biológica a mais dentro do rol da diversidade natural composta por bilhões de organismos, pois à nossa essência animal foi adicionada, sem substituí-la, o traço social. Nós, humanos, somos essencialmente seres sociais que continuam existindo não apenas por seus vínculos societários, mas também por seus vínculos com a natureza, uma dependência que é tão natural quanto eterna (TOLEDO; BARRERA-BASSOLS, 2015, p.27).

É claro que a sobrevivência da espécie humana muito se deve a sua condição sociocultural, mas não unicamente a esse aspecto. $\mathrm{O}$ êxito alcançado por esse mamífero tão frágil deve-se, sobretudo, a uma adequação de sua inteligência com o meio em que se encontra, isto é, o homem aprendeu a viver e conviver com a natureza, afinando o uso da sua inteligência com os recursos que esta natureza lhe oferecia. O ser humano é, no rol da espécie dos mamíferos, o mais frágil, sobretudo nos primeiros anos de vida, depende da mãe, de um adulto ou um cuidador por um longo período de tempo para manter-se vivo . Além do mais, o homem não possui armas naturais, isto é, garras afiadas, dentes poderosos ou sequer uma força física que possa equipará-lo a outros mamíferos, como, por exemplo, o leão ou o búfalo.

Nesse contexto, o mamífero humano desenvolveu duas formas de condutas que o diferenciam de outras espécies animais, assim como também de outros mamíferos. Estas duas formas de conduta são a conduta inata e a conduta adquirida, sendo a conduta inata aquele comportamento que nasce com o homem, aquele tipo de conduta que lhe é imposto pela natureza. E a conduta adquirida é o desenvolvimento de um comportamento aprendido, adquirido com o passar do tempo e com as experiências que o homem ao longo de sua história trava com a natureza (SANDY, 2001, p.4). Portanto, o êxito da espécie humana está justamente em esta ter sabido relacionar, de forma harmoniosa, sua conduta inata com sua conduta adquirida, obtendo, assim, vantagem considerável em relação às outras espécies. A esse respeito, o arqueólogo australiano Gordon Childe ilustra:

O ser humano pode ajustar-se a um número maior de ambientes do que qualquer outra criatura, multiplica-se infinitamente mais depressa do que qualquer mamífero superior ,e derrota o urso polar, a lebre, o gavião e o tigre em seus recursos especiais. Pelo controle do fogo e pela habilidade de fazer roupas e casas, o homem pode viver, e vive e viceja, desde os polos da Terra até o Equador. Nos trens e au- 
tomóveis que constrói, pode superar a mais rápida lebre ou avestruz. Nos avióes e foguetes pode subir mais alto do que a águia, e, com os telescópios, ver mais longe do que o gavião. Com armas de fogo pode derrubar animais que nenhum tigre ousaria atacar.

Mas fogo, roupas, casas, trens, automóveis, avióes, telescópios e armas de fogo não são partes do corpo do homem. Eles não são herdados no sentido biológico. O conhecimento necessário para sua produção e uso é parte do nosso legado social. Resulta de uma tradição acumulada por muitas gerações e transmitida, não pelo sangue, mas através da linguagem (falada e escrita).

A compensação que o homem tem pelos seus dotes corporais relativamente pobres é o cérebro grande e complexo, centro de um extenso e delicado sistema nervoso, que lhe permite desenvolver sua própria cultura (CHILDE, 2010, p. 40-41).

A capacidade do homem em adaptar-se ao meio onde se encontra, a partir do uso de seu cérebro, é inegável para seu êxito existencial. Mas a sociedade, modernizada e tecnologizada, parece ter há muito se esquecido dessa verdade e no ímpeto da autossuficiência se viu no direito de não só usar, mas abusar da natureza e do meio ambiente. Em outros termos, a sociedade moderna parece ter perdido a sua memória biocultural. Nesse sentido, Toledo e Barrera-Bassols assim se expressam:

Se o homo sapiens conseguiu permanecer, colonizando e expandindo sua presença na Terra, é porque foi capaz de reconhecer e aproveitar os elementos e processos do mundo natural, um universo que encerra uma característica essencial: a diversidade. Essa habilidade se deve a manutenção de uma memória, individual e coletiva, que conseguiu se estender pelas diferentes configurações societárias que formaram a espécie humana. Esse traço evolutivamente vantajoso da espécie humana tem sido limitado, ignorado, esquecido ou tacitamente negado com o advento da modernidade, que constitui uma era cada vez mais orientada por uma vida instantânea e pela perda da capacidade de recordar (TOLEDO; BARRERA-BASSOLS, 2015, p.2728).

Essa afirmação tem caráter tanto grave quanto verdadeiro, pois, se olharmos a realidade atual da Amazônia atual e de certa forma de todo o planeta, veremos que de fato o homem moderno se esqueceu não só das relações vetustas que a humanidade trava com a natureza, mas também de repassar essas verdades aos seus filhos e netos, isto é, relegou a tradição a objetos de relicário, coisas antigas que não 
têm uso prático na atualidade e, portanto, não servem. É nesse sentido que os povos considerados primitivos têm muito a nos ensinar, pois eles não conhecem a natureza do ponto de vista científico-tecnológico, mas a conhecem como quem conhece um ente querido, um membro da família. Esses povos vivem com a natureza e vivem, por assim dizer, a natureza. São povos em plena vivência de suas tradições, basta para isso nos atentarmos para as lendas e os mitos dos povos da floresta, pois a criação do mundo, as entidades da floresta, a origem dos animais e das plantas, a criação dos clãs estão presentes aí. Segundo o livro sagrado SEHAYPÓRI, do povo Saterê-Mawé,

No começo só existiam as forças cósmicas (Monã), a classe dos deuses: Tupana, o deus do Bem, e YURUPARY o deus Mal. Eles criaram os seres estrelares que vivem espalhados no Atapy (universo) e que são os corpos luminosos que aparecem na escuridão da noite (YAGUARÊ YAMÃ, 2007 (p. 2).

Como podemos constatar, os povos considerados primitivos têm uma vivência tão próxima da natureza que o mundo e seus mistérios se explicam de maneira tão simples quanto natural, pois, como podemos perceber na citação acima, as coisas nascem sempre de um pai e de uma mãe, como ocorre com os seres humanos e animais.

Nesse sentido, os povos da floresta estão em plena harmonia com a natureza que os cerca e não há duvidas sobre a origem das coisas, tudo se explica na simplicidade do mito.

\section{UMA VISÃO ANTROPOMÓRFICA DO MUNDO}

Os povos amazônicos, considerados primitivos, nutrem pela natureza e pelo meio ambiente uma verdadeira devoção, sobretudo pelo motivo de estarem, de certa forma, inseridos em um contexto existencial em que a religiosidade e a sacralidade estão presentes no dia a dia. O natural é apenas uma manifestação do sobrenatural, isto é, o natural e o sobrenatural são, para esses povos, apenas dois aspectos da mesma realidade. Assim, dá-se uma visão antropomórfica do mundo, o homem entendendo-se como parte da natureza, que vê nesta mesma natureza 
características próprias do ser humano, é, por assim dizer, certa humanização da natureza. Filippo Selvaggi, professor emérito da Universidade Gregoriana de Roma, afirma que

A concepção antropomórfica se desenvolve, depois, espontaneamente numa concepção mágica e dá origem ao exercício da magia, à medida que o homem pensa poder influir nos acontecimentos do mundo através dos mesmos meios com que influi nos movimentos do próprio corpo e sobre outros semelhantes, isto é, mediante o desejo e a vontade, a palavra, a oração, o gesto, a ordem. Deste modo mediante a arte mágica, procura o homem estender e converter em própria utilidade a comunhão e a simpatia cósmicas que estão na base da mentalidade primitiva (SELVAGGI, 1988, p. 34-35).

Para esses povos, considerados por nós, homens tecnologizados, primitivos, a natureza é mais que uma fonte de vida, ela é a própria vida. Essa afirmação fica cada vez mais clara quando partimos dos estudos antropológicos, realizados no território amazônico, estudos estes efetuados por respeitados pesquisadores que ao longo de décadas se propõem a conviver de perto com a realidade desses povos. Povos estes que trazem, em relação a nós e mesmo entre si, enormes diferenças culturais, sociais e étnicas, dentre os quais se encontram os caboclos das diversas comunidades ribeirinhas, além das mais diversas etnias indígenas que ali ainda habitam, os chamados "povos da floresta".

Para esses povos da floresta, a ligação com a terra e com tudo o que a ela está atrelado (animais, frutos, plantas, recursos hídricos etc.) é algo que vai muito além do uso, ou seja, é uma questão de afetividade, é algo que supera infinitamente a ideia de posse (tão reverenciada nas sociedades ditas modernas), é algo que só pode ser compreendido a partir de um olhar profundo para a maneira como essas culturas são constituídas. A esse respeito, Selvaggi afirma:

Por isso, no primeiro estádio da evolução psíquica humana, quer individual em cada criança ou coletiva nos povos primitivos, tem-se uma explicação antropomórfica: quer dizer, o homem procura tornar inteligível o mundo e os fenômenos que se sucedem no mundo, reconduzindo-os ao que ele próprio experimenta na própria consciência, ao modo com que ele explica as suas ações e os movimentos do seu corpo. Por outras palavras, o homem projeta-se a si mesmo no mundo, nas coisas que o circundam, atribuindo-lhes os mesmos 
sentimentos, forças e intenções que em si mesmo experimenta, até uma personificação de todas as coisas que o circundam, que agem e mudam.

Surge assim a visão antropomórfica e animística do mundo, baseada, não só e, sobretudo na necessidade de explicação, mas ainda num sentimento de comunhão, participação e simpatia para com o mundo em que estamos e vivemos, e para com as coisas que existem conosco no mundo (SELVAGGI, 1988, p.34).

Para essas populações, portanto, a construção da cultura e da história não é algo que se aprende na escola, mas é um saber recebido no seio da comunidade, é familiar, passado de pai para filho, na maioria das vezes na forma oral. Não se trata de uma cultura documental, uma cultura baseada nos registros oficiais do Estado, antes, é uma cultura baseada na confiança e no respeito, confiança em quem repassa a história de forma oral, confiança de que aquele que conta fala a verdade e é fiel ao que ouviu de seus antepassados. Essa confiança nasce justamente do respeito ao ancião e a sua experiência de vida, experiência que tem suas bases seguras na sabedoria adquirida com o passar dos anos. Nesse sentido, podemos encontrar implícita, em várias lendas e fábulas que fazem parte do imenso mundo da mitologia dos povos indígenas, uma lição: "quanto mais se vive mais se aprende a viver". Parece evidente que, para os chamados povos primitivos, o tempo de vida aproxima o homem da sabedoria, pois o aproxima do conhecimento da natureza, possibilitando-lhe interagir com a natureza, tirando dela o necessário para seu sustento e mantendo com ela uma relação de respeito e gratidão. Uma fábula do povo Saterê- Mawé:

O Tatu e a Onça combinaram de viajar. Durante a viagem a Onça sempre dando uma de esperta, provocava o Tatu para caçoar dela, com a intenção de comê-lo. O Tatu que era vivido, não dava pretexto para que a Onça o comesse. Quando chegou perto de uma toca o Tatu começou a zombar da Onça e entrou no buraco o mais rápido possível. Quando a Onça meteu a cabeça no buraco para abocanhá -lo o Tatu furou os olhos dela com as unhas afiadas. A Onça cega, não atormentou mais nenhum bicho da floresta e dependia da caridade dos outros para se alimentar (YAGUARÉ YAMÃ,2007, p.146).

Como podemos notar, o tatu, apesar de ser inferior em força e habilidade na escala natural, era "vivido", tinha experiência e por isso havia adquirido sabedoria, 
o que lhe possibilitou vencer a onça, muito mais rápida e forte, usando um artifício, uma estratégia que só a vivência proporciona, só o tempo possibilita.

Os povos da floresta nutrem pela natureza e, portanto, pela terra em que nasceram e que seus ancestrais desbravaram, onde trabalharam, lutaram e as deixaram por herança uma concepção bem diferente daquela que o homem que se considera civilizado nutre. Para os povos da floresta, eles não apenas habitam um território, mas, sobretudo, fazem parte do território, sentem-se parte integrante da própria terra. Em outras palavras, preservam sua memória biocultural.

\section{O MITO DO PROGRESSO}

Não é sem motivo que essas sociedades tribais, assim como algumas comunidades ribeirinhas, evitam o denominado progresso. A ideia de progresso, como já falamos anteriormente, traz em si o "selo" da mudança, e em geral essa mudança, proposta pelo desenvolvimento, fere o que para essas sociedades há de mais sagrado, a saber, a terra e o meio ambiente, a natureza, coisas que se encontram irremediavelmente ligadas à tradição.

A ideia de progresso, forjada no bojo do século XIX, caiu muito bem no paladar do homem contemporâneo, dando-lhe, assim, um falso sentido de melhoramento da realidade: toda vez em que ouvimos o termo "progresso", pensamos logo em desenvolvimento e em melhoria de algo. Nesse sentido, à medida em que essa ideia ganha positividade, a ideia de regresso se torna cada vez mais negativa pois, para o homem moderno, o progresso representa mudar para melhor.Mas será assim mesmo?

Progredir é tornar as coisas melhores, mais úteis. Mas essas sedes de mudanças rápidas e muitas vezes drásticas levaram o homem moderno e contemporâneo a uma espécie de labirinto cuja saída não sabe. Primeiro, nos campos da economia e da política e depois adentrou em outros campos como, por exemplo, o do meio ambiente. Em nome de uma política progressista e de uma economia cada vez mais forte, a vida humana e a saúde do planeta foram e continuam sendo colocadas em risco. É em nome de uma política do progresso e de uma economia forte que grande 
parte da Amazônia vem sofrendo sérios problemas ambientais. É sob esse intuito que inúmeros povos (ribeirinhos, nações indígenas, caboclos) são expulsos de sua terra, de seu chão, isto é, de sua vida.

O progresso tornou-se, portanto, uma espécie de mito, pois em decorrência de lucros têm-se plantado "ilusões no fértil solo da degradação ambiental". José Bové, a esse respeito, escreve um artigo intitulado "Precisamos Acabar com a Ideologia do Progresso", no qual afirma:

O que constitui a base do movimento planetário de questionamento da globalização e da vontade de dizer que é preciso desfazer o desenvolvimento é a necessidade de acabar com a ideologia do progresso. Ela é responsável por uma espécie de mito, segundo o qual existe uma dada situação de partida que pode ser melhorada pelo que a humanidade é capaz de fazer. Esse grande mito do século XIX foi a ideologia dominante, constituída, ao mesmo tempo, pelos liberais e pelos marxistas, constituindo verso e reverso da mesma moeda (BOVÉ, 2009, p.19).

Deve aqui ficar claro que Marx não concorda com as teorias liberais e até mesmo chega a defender a relação sadia do homem com a natureza, sobretudo nos seus manuscritos econômicos e filosóficos.

\section{UM OUTRO OLHAR SOBRE A IDEIA DE REGRESSO}

Entre os povos da floresta, a ideia de regresso tem sentido bastante positivo, pois ela pode significar reencontro, volta às origens. Regressar para as comunidades da floresta é reencontrar, rememorar. Entre os povos considerados primitivos ou rústicos é, acima de tudo, uma rememoração, isto é, um relembrar as origens, é uma retomada daqueles ensinamentos, daquela sabedoria ensinada pelos pais e avós. Esse reencontro com a tradição e com as antigas sabedorias possibilita uma convivência harmônica com a natureza, é a recuperação da memória biocultural.

A ideia de regresso para tais culturas (os povos considerados primitivos, indígenas, caboclos e ribeirinhos) marca um reencontro com as essências, a saber, um reencontro com a verdadeira identidade. E é por esse motivo que há tristeza 
quando um membro da comunidade sai do seu seio, ao passo que o regresso desse membro é motivo de festejo e alegria, pois era um membro que estava perdido, desterrado, longe dos seus e de sua essência e agora regressa para recuperar sua identidade que por sua vez está extremamente ligada ao chão em que nasceu, à terra da qual se alimentou, aos rios em que pescou e banhou-se, ao ar em que fortaleceu seus pulmões. Regressar é não apenas o reencontro com o passado, mas também o encontro com o novo, com as mudanças oferecidas pela natureza humana e pela natureza fora do homem. O regresso não só provoca o reencontro com a memória dos antepassados, mas o encontro com os novos membros da comunidade, parentes nascidos, enquanto se esteve fora. Mas essa realidade se dá por vezes, também, no âmbito das grandes comunidades humanas, pois alguém que deixa seu país de origem e vai viver em outro país, por melhor situação em que se encontre, sempre - ou quase sempre - tem uma tendência natural a regressar e a rever parentes e amigos, isso denota a ligação quase que natural da terra natal com a identidade do indivíduo, identidade essa que só se constitui plenamente em contato com seu povo, sua terra, sua gente.

O etnólogo Marshall Sahlins afirma, a partir de seus estudos, que "A economia tradicional se insere nas relações sociais. Sua base de ação não é a empresa, mas a família, a comunidade" (SAHLINS, p.1971).

É a família e a comunidade que conferem identidade para as comunidades consideradas primitivas ou tribais. A esse respeito, Edward Goldsmith pronuncia um alerta ao homem moderno - tão distanciado da solidariedade e da afetividade comunitária - em um texto que tem por título "Antes do Desenvolvimento". Ele enuncia:

Para um homem tribal, a família e a comunidade, bens inseparáveis do mundo natural, oferecem todos os benefícios. A incrível solidariedade que liga os membros entre si evita que passem fome ou caiam na miséria, a não ser que o grupo todo sofra esses males. E a pior punição para um membro que transgride a lei tradicional é, sem dúvida, a expulsão da comunidade. Em 1970, nas ilhas Comores², garantiram-me que um ${ }^{3}$ wahamatsa condenado ao ostracismo e menosprezado era um homem morto. (GOLDSMITH, 2009. p 42).

2 É um país africano que não possui fronteiras terrestres, estando localizado relativamente próximo a Moçambique e Madagascar (FRANCISCO, 2016, p.1).

3 Membro nativo de uma tribo ou de um povo primitivo das Ilhas Comores (GOLDSMITH, 2009, p.41). 
Fora da comunidade de origem, de sua terra, de seu chão, de seu povo, longe do contato com a natureza, o homem da floresta, os povos considerados primitivos ou tribais, sente que sua vida, por assim dizer, mergulha em um ritual fúnebre, e que algo de si desce à sepultura.

\section{O POSITIVISMO E A IDEIA DE PROGRESSO}

A ideia de progresso, assim como é compreendida hoje, não só fere as relações do homem com o meio ambiente, como também possibilita ao homem se utilizar da natureza e de seus recursos de forma maléfica ou no mínimo de maneira irresponsável. O termo progresso, como hoje é compreendido e utilizado, tem suas bases fundamentais no positivismo, isto é, corrente filosófica, fundada por Augusto Comte no século XIX. Ao publicar o seu livro "Curso de Filosofia Positiva" entre os anos de 1830 e 1842, Comte funda uma nova forma de pensar a sociedade, e a essa nova forma ele denomina de "Física Social" e é exatamente nela que está a essência do seu pensamento, a saber, um pensamento baseado na observação científica da sociedade e na comprovação. Para Comte, a história da humanidade pode ser dividida em estágios (PÉREZ, 1988, p.213). Por esse motivo ele desenvolve a denominada teoria dos três estágios, uma teoria que divide todo o processo de compreensão da humanidade em relação ao conhecimento em três grandes etapas (PÉREZ, 1988, p.213). O primeiro estágio, Comte denomina de teológico ou mítico, neste estágio o homem explica todos os acontecimentos naturais e sociais como sendo obra dos deuses ou de um Deus. O segundo estágio é o filosófico ou metafísico, estágio em que o homem já começa a utilizar a razão mas ainda está preso a certas realidades metafísicas que pouco ou nada têm a ver com a realidade objetiva das coisas. $\mathrm{O}$ terceiro e último estágio é o mais elevado de todos, é o estágio científico ou positivo. Estágio em que o homem já não se prende a superstições infundadas e nem busca a essência abstrata das coisas, mas acima de tudo está preocupado em descobrir e mostrar a verdadeira realidade das coisas, como elas ocorrem, por que elas ocorrem e quais as consequências desses acontecimentos.

A partir dessa teoria formulada por Augusto Comte, podemos perceber que há uma ideia de progresso latente no desenvolvimento da humanidade, na forma 
de o homem compreender a realidade em sua volta e na maneira de compreender o próprio movimento social. Progresso, aqui, portanto, seria passar de um estágio menos evoluído a outro mais evoluído, significando dizer que os povos que conservam uma visão mítica da natureza estão em um estágio menos evoluído do que aqueles que têm uma visão mais científica, logo, estes se denominam evoluídos e modernos enquanto aqueles são denominados primitivos.

Talvez seja por esse motivo que o homem que produz conhecimentos científicos, desenvolvidos nos grandes centros urbanos, formado nas mais famosas universidades do mundo se ache mais apto a decidir qual o melhor tratamento a dar para a Amazônia e suas riquezas naturais do que aquele homem nascido às margens dos grandes e pequenos rios, nas comunidades caboclas ou ribeirinhas, ou ainda aqueles povos indígenas que, ao que nos parece, ainda estão num estágio que não permite a possibilidade de decisão acertada a respeito da realidade e da natureza. Aquele homem da ciência se vê no direito de decidir sobre a vida daqueles (povos da floresta) que não são capacitados a decidir qual o melhor uso a ser feito da natureza com a qual eles não só interagem há séculos, mas da qual eles se sentem parte integrante. Não é sem motivo que na bandeira brasileira está explicito o lema positivista: "Ordem e Progresso".

$\mathrm{Na}$ concepção moderna, ou seja, se olharmos através das lentes que desvendam o mundo para a modernidade, falar de progresso significa, entre outras coisas, falar de industrialismo e falar em industrialismo remete imediatamente à ideia de civilização. O industrialismo é, grosso modo, uma grande economia de trabalho em vista da crescente produção de produtos que não só satisfaça nossas necessidades, como também os nossos desejos (DOLABELA, 2013, p, 1). Já a civilização é a busca de satisfação das mais remotas necessidades e desejos do ser humano, necessidades estas muitas vezes não necessárias, isto é, necessidades muitas vezes criadas. A esse respeito, o filósofo Bertrand Russell afirma:

Podemos definir o que se chama civilização como a busca de objetos não biologicamente indispensável à sobrevivência. A civilização surgiu com o aparecimento da agricultura nos deltas férteis dos grandes rios, sobretudo no Egito e na Babilônia (RUSSELL, 1979. p. 27).

Sobre o industrialismo, Bertrand Russell se pronuncia nos seguintes termos: 
O homem que primeiro pensou em arar o solo antes de semear deu o primeiro passo no sentido do industrialismo: arar a terra é algo que em si não satisfaz qualquer das nossas necessidades ou desejos, mas reduz o volume de trabalho exigido para saciar a nossa fome. O industrialismo é a ampliação dessa prática de fazer ferramentas, até que as ferramentas vieram a dar na moderna maquinaria (...). A essência do industrialismo é o emprego de complexa maquinaria e outros meios (tais como ferrovias) de reduzir o trabalho total da produção (RUSSELL, 1979, p. 16-22).

É até certo ponto curioso, porém não sem propósito, que Russell aborde que tanto a industrialização como a civilização têm profunda relação com o surgimento da agricultura, pois, de fato, a civilização surge com o domínio da terra, em outras palavras, surge com o domínio da natureza - à medida que o homem descobre que, após semear, ele pode esperar para colher os frutos já denota certo controle sobre o meio em que se encontra. De forma análoga, a fabricação de ferramentas e seu uso para arar a terra, a fim de obter melhor resultado com menor esforço, tornam o homem mais poderoso diante da natureza, isto é, ao usar artifícios para tornar a terra mais produtiva, o animal pensante exerce maior domínio sobre a terra, sobre a natureza.

É, sobretudo, o fato de usar a inteligência para o domínio da natureza que diferencia o homem dos outros animais, dando a ele a sensação de poder e um sentimento de libertar-se da "escravidão" à qual a natureza o submetia (o homem à mercê da natureza). A esse respeito, Russell também se pronunciou nos seguintes termos:

Ao reduzir a escravidão do homem para com a natureza, o industrialismo possibilitou muitas coisas de grande valor, que só parcialmente eram possíveis em estágios anteriores. A condição de meramente manter-se vivo o homem compartilha com os animais inferiores, e nisso não se eleva acima deles em nenhum aspecto importante. $\mathrm{O}$ que eleva o ser humano acima do nível dos animais é sua capacidade mental, que encerra em si desejos não meramente materiais (RUSSELL, 1979, p.26).

4 Com o termo escravidão quer significar a submissão do homem à natureza nos períodos em que a ciência e os outros tipos de conhecimentos não possibilitavam ao homem compreender a natureza, seu funcionamento, sua lógica para, assim, dominá-la, exemplo, a pré- historia. 


\section{O HOMEM TAMBÉM É NATUREZA}

A ideia de progresso, como entendida hoje, vai na contramão da tradição, da culturae por esse motivo fere mortalmente a memória biocultural. No que se refere à Amazônia - assim como em outras partes do mundo -, o progresso passou a ser não só o uso moderado e harmônico dos recursos naturais, para uma subsistência, mas, acima de tudo, o abuso desses mesmos recursos em nome de um lucro econômico cada vez maior e de forma indiscriminada e irresponsável. A esse respeito, o papa Francisco nos alerta em sua carta eclesiástica, "Laudato Si": "esquecemo-nos de que nós mesmos somos terra. O nosso corpo é constituído pelos elementos do planeta; o seu ar permite-nos respirar, e suas águas vivifica-nos e restaura-nos" (FRANCISCO, 2015, p. 3).

Esquecer! É exatamente isso que o homem contemporâneo tem feito em relação ao meio ambiente. Esqueceu-se que o uso irresponsável da natureza e de seus ricos recursos traz como consequências prejuízos drásticos para a humanidade. É preciso imediatamente retomar a rota e redescobrir como parte integrante da natureza que está sendo destruída ferozmente.

Em 1970, o papa Paulo VI já nos alertava sobre o tema ecológico, sobretudo no contexto amazônico, dizendo que o efeito de uma exploração industrial desordenada em busca de um suposto progresso poderia causar uma crise com consequências dramáticas para o ser humano. Conforme lembra o papa Francisco, o papa Paulo VI dizia da

Necessidade urgente de uma mudança radical no comportamento da humanidade, porque os progressos científicos mais extraordinários, as invenções técnicas mais assombrosas, o desenvolvimento econômico mais prodigioso, se não estiverem unidos a um desenvolvimento social e moral, voltam-se necessariamente contra o homem (FRANCISCO, 2015, p.3).

O papa Paulo VI foi coerente em sua afirmação, pois é uma verdade também conhecida pelos povos da floresta. O homem da floresta amazônica sabe, muitas vezes por intuição e por experiência, que o mau uso dos recursos naturais pode se transformar em arma mortífera contra o próprio homem. O que Paulo VI fez, na ocasião, foi dar notoriedade a um grito que há muito ecoava e ecoa da floresta amazônica e de outras partes do mundo. 
O verdadeiro progresso não pode levar à degradação da natureza e por consequência à destruição do homem, ao contrário deve ser o uso consciente e respeitoso dos recursos que a mãe terra nos oferece gentilmente. Sobre isso, continua o papa Francisco dizendo-nos que João Paulo II, um dos homens mais respeitados do mundo, não só pelo seu cargo religioso, mas pelo seu grau de compreensão do homem e por sua profunda reflexão filosófica e coerência, ao afirmar que

O progresso humano autêntico possui um caráter moral e pressupõe o pleno respeito pela pessoa humana, mas deve prestar atenção também ao mundo natural e ter em conta a natureza de cada ser e as ligações mútuas entre todos, em um sistema ordenado (FRANCISCO, 2015, p. 16).

Logo, compreendemos que deve haver um resgate do sentido de progresso, mas, para isso, se faz extremamente necessário um regresso à memória biocultural, isto é, uma redescoberta do próprio homem como ser integrante do meio ambiente, a redescoberta do homem que interage e se torna parte efetiva da natureza, sem que, para isso, perca sua característica sociocultural, sem prejuízos para a ciência ou para a intelectualidade de maneira geral.

A ideia de regresso, aqui exposta, não significa de maneira nenhuma uma estagnação científica ou cultural, tampouco uma involução, antes, é uma revisão e reavaliação de conceitos e atitudes que possibilitem ao homem reaprender a viver no planeta, conviver no meio ambiente e a atualização da memória biocultural. É, sobretudo, uma desconstrução da ideia desvirtuada de progresso para reconstruí-la dentro de parâmetros sociais, culturais e morais que respeitem a vida e reintegrem o homem ao meio ambiente do qual ele hoje se sente fora.

Nesse sentido, temos muito a aprender com os povos da floresta. Em uma época em que todas as lentes estão focadas na Amazônia, faz-se necessário antes ouvir as vozes das populações que lá habitam, pois elas são o que são por causa de sua integração com a natureza, por sua vivência harmônica com a floresta amazônica e, sobretudo, por saberem respeitá-la e amá-la como a um membro da família. É preciso compreender a Amazônia entre o progresso e o regresso. É preciso pensá-la desvinculada de lucros econômicos antes que a própria economia, extraída dela, já não se sustente mais. É preciso "regressar" para progredir, o regresso, a volta a casa 
(eco) é imprescindível para que façamos o progresso, o conhecimento (logia), pois só assim teremos de fato uma séria ecologia. O regresso a casa é sempre motivo de festa.

\section{CONSIDERAÇÕES FINAIS}

Precisamos recuperar a memória biocultural. É urgente reavivar a lembrança de que somos parte integrante da natureza, pertencemos à biodiversidade. $\mathrm{O}$ fato de nos encontrarmos em uma posição aparentemente superior em relação aos outros seres não nos faz seres autossuficientes.

Por um capricho do acaso - como querem alguns - ou por obra da própria natureza, o homem passou a ser uma espécie de administrador da vida sobre a terra, pois nenhum ser vivo interfere e modifica tanto o meio ambiente como o ser humano, mas essa realidade não o autoriza a cometer abusos contra o meio em que habita e, em última instância, contra si mesmo.

O resgate da memória biocultural é a opção para o homem se reencontrar harmonicamente com o meio que habita e com as inúmeras formas de vida que com ele dividem a rica biodiversidade. E, a partir de tal resgate, poder repensar as relações de progresso e desenvolvimento da Amazônia, sobretudo, no que se refere a esse tão rico e maravilhoso universo, denominado Amazônia.

\section{REFERÊNCIAS}

BOVÉ, J. Desfazer o Desenvolvimento para Refazer o Mundo. São Paulo: Cidade Nova, 2009.

CHILDE, G. Fundamentos de Filosofia. São Paulo: Saraiva, 2010.

DOLABELA F. Educação, Industrialismo e Empreendedores; Instituto Millenium. Disponível em: <http://www.institutomillenium.org.br/artigos/educacaoindustrialismo-empreendedores/>. Acesso em: $01 \mathrm{dez} .2016$.

GOLDSMITH, E. Desfazer o Desenvolvimento para Refazer o Mundo. São Paulo: Cidade Nova, 2009. 
FRANCISCO, P. Laudato Si. São Paulo: Paulinas, 2015.

FRANCISCO, W. C. Comores: Brasil Escola. Disponível em: < http://brasilescola.uol. com.br/geografia/comores.htm > . Acesso em: 29 nov. 2016.

GOLDSMITH, E. Antes do Desenvolvimento (Desfazer o Desenvolvimento Para Refazer o Mundo). São Paulo: Cidade Nova, 2009.

PÉREZ, R. História Básica da Filosofia. São Paulo: Nerman, 1988.

RUSSELL, B. Perspectivas da Civilização Industrial. Rio de Janeiro: Zahar, 2007.

SELVAGGI, F. Filosofia do Mundo. São Paulo: Loiola, 1988.

SANDY. A Conduta Humana e os Fatores que a Determinam. Disponível em: $<$ http://www.resumosetrabalhos.com.br/a-conduta-humana_1.htm $>$. Acesso em: 05 dez. 2016.

SAHLINS, M. Tribal Economics. Garden City: Economic Development and Social Chang. 1971.

TOLEDO, V. M.; BARRERA-BASSOLS, N. A Memória Biocultural. São Paulo: Expressão Popular, 2015.

YAMÃ, Y. Sehapóri: o Livro Sagrado do Povo Saterê-Mawé. São Paulo: Petrópoles , 2007.

Recebido em: 2015-08-13 Aceito em: 2016-12-08 